\title{
HOW POLICY IMPACTS ON PRACTICE AND HOW PRACTICE DOES NOT IMPACT ON POLICY
}

by Frank Coffield*, Sheila Edward*, Ian Finlay ${ }^{+}$, Ann Hodgson*, Ken Spours*, Richard Steer* and Maggie Gregson\#

* Institute of Education, University of London

+ University of Strathclyde

\# University of Sunderland

Address for correspondence: Professor Frank Coffield, LEID, Institute of Education, University of London, 20 Bedford Way, London WC1H OAL. email: F.Coffield@ioe.ac.uk

TLRP Project: The impact of policy on learning and inclusion in the learning and skills sector

Submission for special TLRP edition of BERJ, Revised March 2007 


\begin{abstract}
Our project attempts to understand how the Learning and Skills Sector functions. It traces how education and training policy percolates down through many levels in the English system and how these levels interact, or fail to interact. Our first focus is upon how policy impacts upon the interests of three groups of learners: unemployed people in adult and community learning centres, adult employees in work-based learning and younger learners on Level 1 and Level 2 courses in further education.
\end{abstract}

Our next focus is upon how professionals in these three settings struggle to cope with two sets of pressures upon them: those exerted by government and a broader set of professional, institutional and local factors. We describe in particular how managers and tutors mediate national policy and translate it (and sometimes mistranslate it) into local plans and practices.

Finally we criticise the new government model of public service reform for failing to harness the knowledge, good will and energy of staff working in the sector, and for ignoring what constitutes the main finding of our research: the central importance of the relationship between tutor and students. 


\section{Introduction}

FC: "What's the most important thing you've learned on this course?" (Painting and Decorating, Level 2) Further Education (FE) College.

Debbie (aged 16): "Work satisfaction .... It [doing the work placement] proved that the whole school was wrong [about me]. They used to say: 'You won't be able to work. You'll be sitting on the dole at home'. But I've proved them wrong. The tutors give you respect here. If they give you respect, you respect them".

Debbie is the only young woman on this course and intends to start a Modern Apprenticeship in Painting and Decorating next September. She also works part-time serving in a 'chippy' on Mondays, Wednesdays and Saturdays, over 16 hours a week on top of her full-time course at College. She has also successfully retaken in College her GCSEs in English and Maths, exams for which she received very poor grades in school.

The above captures a very significant but unsung achievement of FE Colleges. They take in students whom no-one else wants to teach, namely, those who have failed to gain five good GCSEs at the age of 16; and, through sheer hard work and through forging more respectful and inclusive relationships, they restore them as human beings who begin to see themselves again as worthy of respect and who can and do succeed in gaining qualifications. Many of these students talk of being neglected and even insulted in schools and they have ended up, after 11 years of formal schooling, as damaged learners with serious gaps in their basic skills.

Such students are some of the most challenging to teach in the whole educational system, but they are not homogenous. Some are both challenging and needy, but the challenges and needs they present vary markedly. Some struggle to read and write English properly or to do arithmetical calculations. Some admit to long histories of truancy, some have either a visual or hearing impairment, some have parents who are 
either alcoholics or long-term disabled, some speak English poorly because they are recent immigrants, some disappear from classes for three weeks into a Detention Centre while their status as asylum seekers is sorted out, and many have to work part-time because their families are poor. Students come with different sets of past experiences and problems, which all interact with each other, and tutors can have up to 20 of them in their classes. The surprise is that FE is so successful with so many of them.

It is not only tutors who are stretched to the full by Entry or Level 1 students, they pose huge problems to policy makers, struggling to stop what they themselves called "the scandal of our high drop out rate at 16" (DfES, 2004:71). The OECD has for years been quietly emphasizing the depth and extent of that scandal in its annual reports, where it compares internationally the participation rates of 17 year olds in education or training. The latest report shows that the UK record is worse than that in Belgium, the Czech Republic, Sweden, Japan, Finland, South Korea, Poland, Norway, Germany, France, Austria, Hungary, the Slovak Republic, Ireland, the Netherlands, Switzerland, the USA, Denmark and Australia (OECD, 2006).

The government response in England is an extensive battery of measures which includes the first ever White Paper on FE (DfES, 2006a); a set of new strategies (eg for people with learning difficulties / disabilities, see LSC, 2006a); 'stretching' targets (eg $90 \%$ of 17 year olds to be in education or training by 2015 , although our major competitors surpass this figure already); initiatives (eg Education Maintenance Allowances, which provide $16-19$ year olds from poor families with up to $£ 30$ per week while they study); new curricula and qualifications (eg 14 specialised Diplomas which are to combine theoretical and practical learning); new 14-19 partnerships between schools and FE Colleges; and new types of institution (eg so far, 46 City Academies, 47 
vocational, specialist schools and 4 Skills Academies). The model of reform underpinning all these changes will be discussed in the final section of this paper, together with the topic which the numerous government texts aimed at this sector have nothing to say about and which constitutes the main finding of our research: the central importance of the relationship between tutor and student.

\section{Background}

The establishment of the Learning and Skills Council (LSC) in England in 2001 marked the attempt to draw together into a new learning and skills sector a broad range of diverse provision for people of all ages in further education colleges, community learning centres and in the workplace. As Steer et al. (2007) discuss, the election of the New Labour government in 1997 brought a new model of governance into public services, associated with the discourse of modernisation (Newman, 2005) and increasing reliance on policy 'levers', such as performance targets, standards, audit, inspection, quality assurance processes and powers to intervene where services are judged to be 'failing'. The operational functions of government were increasingly contracted out to NonDepartmental Public Bodies, such as the LSC, but government retained the role of "a regulator of services, setter of standards and guarantor of quality" (Newman, 2001:83).

Since then, an unending and heavy stream of policy and structural changes has continued to affect those who learn, teach and manage provision in the post-compulsory sector, as we have described in other publications (e.g. Coffield et al., 2005; Edward et al., 2007; Hodgson et al., 2005) from this ESRC Teaching and Learning Research Programme project, The impact of policy on learning and inclusion in the Learning and 
Skills Sector. At the time of writing, yet more change is foreshadowed and some of the main examples are mentioned here. The LSC has reorganised its structure from 47 local LSCs into 148 Local Partnership Teams; the fledgling Quality Improvement Agency for Lifelong Learning (QIA) has launched its improvement strategy (QIA, 2007) ; the LSC is consulting on its Framework for Excellence (LSC, 2006b) and promises further documentation and guidance on implementation by 2007; and the recommendations of the final report of the Leitch Review of skills "will have a significant impact on Further Educational colleges and providers", by requiring them to be far more responsive to employers and individuals in a demand-led system (2006: 84).

Our project ${ }^{1}$, running from January 2004 until July 2007, focuses on three groups of learners who have been poorly served by their previous schooling: unemployed people in adult and community learning centres $(A C L)$, adult employees in work-based learning (WBL) and younger learners on Level 1 and Level 2 courses in further education colleges (FE). We are also concerned with the perspectives of the policy-makers at all levels in the sector from national through regional to local.

Figure 1 shows the range of participants who will have contributed to our research over the 43 months. Each level contributes to understanding the ways in which policy percolates down to practice, and without understanding the intervening levels between policy-making and practice in the classroom, we could not hope to achieve our ultimate aim of suggesting what an effective and equitable learning and skills system could look like.

\section{INSERT FIGURE 1 HERE}


The evidence of impact (or lack of impact) is to be found primarily in the sites where learning takes place, and therefore the main focus of our data collection has been the learners, tutors and course managers in 24 learning sites, 12 in London and 12 in the North East of England. Between Spring 2004 and Summer 2006, we scheduled 104 site visits, five to each of the eight college courses in our sample, and four to each of the eight adult and community learning $(\mathrm{ACL})$ and the eight work-based learning $(\mathrm{WBL})$ sites. On each visit, we aimed to interview up to six learners, their tutor and the manager of their course, including, in the WBL sites, union learning representatives (ULRs) and line managers involved in the initiative. Figure 2 shows the breakdown of the 559 interviews conducted during these visits.

\section{INSERT FIGURE 2 HERE}

To understand the impact of policy, however, it was necessary to trace it back to source, talking to the officials forming and issuing policy. The project began with an analysis of key policy documents and an intensive series of confidential interviews with officials, exploring how they believed policy 'levers' were working; further interviews have been conducted throughout; and in the closing months of the project we shall be returning to the same organisations to update their perspective and discuss our emerging findings. Data collection at the European level is also scheduled for early 2007. Figure 3 shows the distribution of policy interviews to February 2007.

\section{INSERT FIGURE 3 HERE}


This paper is concerned primarily with the impact of policy on the learning sites, for each of which detailed, structured reports were prepared from the analysis of the transcribed data by two of the researchers who had made those site visits. It also draws on other outputs from the project, which contain more detail than is possible here. ${ }^{2}$

The structure of this paper reflects the duality in the data we have collected and analysed. Firstly, we explore how policy 'levers' - and in particular, funding, targets and policy initiatives such as Skills for Life $(S f L)$ - are impacting on the practice of tutors and managers, and affecting the lives of the learners they support. We also asked staff to identify all the factors which affect teaching, learning, and inclusion in the settings where they work, and these are discussed in the second part of this paper. Like the teachers interviewed by Nias (1989) and the teachers and nurses interviewed by Stronach et al. (2002), the tutors and managers in our project described their 'ecologies of practice': their own professional identity; their learner-centred ideologies; their institutional cultures and the sub-cultures of their teaching team; and their beliefs about what constituted 'good practice' in that setting ${ }^{3}$. They have also identified demands made upon them which are not directly attributable to government policy (eg, from Awarding Bodies) and environmental and economic factors (eg, in the local labour market). The impact of all these factors reminds us that policy makers are not writing upon a blank slate, but on a page already taken up with 'ecologies of practice', past and present initiatives and specific local factors. In the closing section, we shall return to a discussion of these two sets of influences on practice and to the government's willingness to offer 'voice' to all groups except the professionals who, from the learners' perspective, make the sector work. 


\section{Policy 'levers'}

Steer et al. (2007) outlined the historical development of policy 'steering' and how policy 'levers' have been used in different combinations in the post-compulsory sector by governments since the early 1990s. In March 2006, the government announced that "the key strategic role for the sector ... is to help people gain the skills and qualifications for employability", which implied "a reconfiguration of the system around this mission" (DfES, 2006a: 21 and 17). All the 'levers' of power in the government's armoury are now to be pulled harder than ever to bring about this transformation. From our data, we identified five important policy 'levers': funding, targets, initiatives, planning and inspection. In this paper space dictates that we concentrate on the first three.

Funding and targets are two of the most powerful 'levers' used in tandem in all areas of our research, sometimes figuring as part of specific policy initiatives. In the FE colleges, targets for retention and achievement were mentioned in almost every staff interview. As one manager said:

Targets focus the mind a lot ... you have an eye on them and the team discusses them, and so do l, endlessly. (B2M3/3)

For tutors teaching Level 1 and Level 2 students, meeting targets for the retention of the minority who were poor attenders used a disproportionate amount of their time and energy. Tutors spent time talking to these learners in person or on the phone, took work to learners' homes or to hospital and, even in colleges with highly developed systems of student support including mentors and counsellors, tutors were chosen as the first port of call for learners with problems which might endanger their progress. 
Middle managers and course leaders also recounted efforts to meet their targets for engaging employers in training, despite considerable employer apathy in some areas. They also explained the perverse effect of some targets: for example, if a youngster came to college to do an FE course in a craft area, impressed his placement employer and was offered an apprenticeship, that was good news for his career and his employer, but bad news for the college, which would be penalised for a poor 'completion' rate on the FE course, even although the same learner was still on their books on the apprenticeship route.

In the ACL settings, funding and targets were closely linked to the $S f L$ initiative. To meet the national target of 1.5 million adults to achieve national certification by 2007 , unprecedented levels of funding were channelled into this area, $£ 3.7$ billion by 2006 and a further projected $£ 2$ billion by 2010 (DfEE, 2001; DfES, 2003). SfL comprises a new curriculum, with new teaching materials, national tests for basic skills learners and new qualifications for those who teach them. Tutors and managers were overwhelmingly positive about being able to expand their services and help more learners. Positive comments from long-serving basic skills managers included:

This is the first time we have had substantial growth. (GM1/2)

It has put basic skills on the map, on the agenda. $\quad(\mathrm{JM} 1 / 1)$

The speed of change had been intense and had brought problems when the distribution of materials and the appointment of new staff could not keep pace with the growth in demand for basic skills classes. Some staff had reservations about the volume of associated paperwork and the value of the National Tests in Literacy at Level 1 and Level 2, on the grounds that they measure only reading and spelling, and ignore writing, speaking and listening. Pursuit of targets also had an impact on the process and content of teaching: 
It is definitely a different type of teaching I'm doing now. I'm teaching towards getting them through those exams. (EM1/1)

The structures of provision were also affected, as mixed ability classes were replaced by classes graded by ability in preparation for Level 1 and Level 2 tests. Interviewees frequently expressed concern about the future of teaching for vulnerable Entry Level and Pre-Entry Level learners who do not contribute to those targets. Although schemes to encourage 'quick-fix' learners, who could take the Level 1 or Level 2 test with only a short course of preparation, were widely used to help hit targets and maximise income, many professionals queried whether these were the people who really needed their help with literacy and numeracy. Others were unhappy with the practice of some providers who offered financial incentives to members of the public and sometimes local government employees, to take these tests and so help them to meet their targets.

In the WBL sites we found that funding, through the Union Learning Fund and the Employer Training Pilots, later Train to Gain, had brought basic skills into the workplace for many who had not had any training before in their working lives. One manager described ETP as

the catalyst that got training started because management did not have to pay for it. (MM3/3)

On these sites, targets were a concern not for the employer, but only for the organisation (usually a college or ACL team) which was providing the tuition. Visiting tutors were largely dependent on the collaboration of ULRs and local managers to ensure that the numbers of learners coming forward to prepare for the national tests remained viable. Sustainability - after the short-term funding ended - was a serious concern for ULRs and managers. In two sites, the employer took over responsibility for ongoing provision, and in another, a Council Department, staff had opportunities to join in wider schemes 
run centrally by the Council. One medium-size employer developed a financial incentive scheme to encourage factory employees to take NVQ and basic skills qualifications, but was still struggling against a shop-floor culture in which learning and qualifications were not valued.

In addition to these two major policy initiatives, $S f L$ and $E T P$, the Education Maintenance Allowance (EMA) was making a big difference to Level 1 and Level 2 learners in FE colleges. Most tutors believed that the additional financial incentive was helping to improve regular attendance, and in a few sites, the award of the bonus was at the discretion of tutors who had linked it to appropriate behaviour, punctuality and participation in class. Learners who received EMA were almost universally glad of it, although many of them were also working part-time to support themselves, and some protested that they would have attended even without the added incentive. We did, however, meet learners who did not qualify for EMA, because of their age, parental income or refugee status, and a few of these were resentful that classmates were being rewarded for good attendance. Tutors confirmed that this measure, designed to improve inclusion, had proved divisive in some groups, and in one setting the teaching team had devised a local merit point scheme, rewarded by gift vouchers if sufficient points were accumulated, to ensure that all learners in the group could work towards the same goal.

What all these three initiatives - EMA, ETP and $S f L$ - had in common was the speedy growth of bureaucracy, in the college or the LSC, to monitor them and hand out the funding. For all three, the benefits were partially offset by the heavy burdens of paperwork on teaching staff. Even in colleges which had set up administrative teams to deal with $E M A$, tutors told us they were frequently asked by learners to intervene with administrators when EMA had been mistakenly withheld, and managers had to learn to 
cope with the irate protests of parents. For ACL teams, changes in the way funding was allocated for $S f L$, such as the introduction of the rule that no intervention of less than nine hours would be funded, caused immense upheaval in the organisation of their provision, especially for teams which had been visiting all local ACL classes and using diagnostic assessment in basic skills as a means of attracting new learners to their service, work which could no longer be funded under the new rules. The paperwork for ETP was also criticised as cumbersome, and funding could be lost if precise details of each learner were not meticulously recorded.

\section{Other factors impacting on learning and inclusion}

Government 'levers' are not the only factors affecting practice in the LSS and those suggested by interviewees were very diverse. We have organised them into five categories, four corresponding to the lower levels of Figure 1:

- the learners who are supposed to be at the heart of the system;

- the individual teaching staff who work with them;

- the team level, including the middle managers; and

- the institutional level, which includes, for example, the provision of central services and resources and the management culture in colleges.

The fifth category includes social, economic, historical, geographical, institutional and labour market factors which constitute the 'local ecology' and the impact of other external parties, such as Awarding Bodies and employers. 


\section{4a Learners}

The expansion of provision at Level 1 and Level 2 in FE, and of basic skills provision in $\mathrm{ACL}$ and WBL, has brought into the system large numbers of learners whose previous experience of schooling has been very negative. In describing their experience of college, many learners contrasted it to their treatment in school: they valued being treated as adults and the support of tutors in helping them achieve qualifications at last. The learners themselves identified their relationship with their tutor as the most important factor in their progress, and our interviews with tutors confirmed that they were constantly adjusting their professional practice to meet the specific and varied needs of learners, whether they were youngsters trying to hide their lack of confidence and fear of failure behind boisterous behaviour, or adults embarrassed by their difficulties with spelling and grammar. A college tutor, talking about her work with Level 1 nursery nurses, expressed succinctly a recurring theme in interviews with basic skills and subject tutors across all our sites:

We have got to get them to that point where they believe in themselves. (A1T1/2)

We found many examples of staff using their professional judgement to create learning cultures in which learners accustomed to failure could learn to thrive, co-operate with their fellow students, keep up their motivation and eventually gain their qualification. Tutors who also taught Level 3 and Level 4 students described how they adjusted their classroom practice, and in our lesson observations, we saw this in action. Level 1 learners could be particularly challenging:

I find it like I'm on a runaway train sometimes and I can't keep up with them. It is fast and furious and you are making sure they're motivated and it is very active. I have to think more on my feet with the Level 1s. (A1T2/4)

The importance of the tutor-learner relationship was perhaps to be expected in the ACL and WBL sites, but in the FE sites we probed for other ways in which colleges made the 
learners feel welcome and included. Although all had measures for obtaining representative student views and had social and sports facilities open to all students, the Level 1 and Level 2 learners we spoke to - with the notable exception of a group of apprentices who liked to hire the college gym for a lunchtime game of football - were not very interested in the wider life of the college. Many said they had part-time jobs and only came to college when they had classes; and a tutor whom we asked about this reluctance to participate suggested that some, particularly at Level 1 , were lacking in social confidence with strangers and only felt safe with their familiar classmates and tutors in the base room where all their classes were held.

\section{4b Tutor Professionalism}

Complying with national and local requirements for evidence of meeting targets and completing paperwork - the elements which Stronach et al. (2002) describe as 'the economies of practice' - has become part of the professionalism of tutors, but those we interviewed also talked about their 'ecologies of practice', ie their traditional values, love of teaching and commitment to their learners:

I've a passion for education and I feel for these students. (B2T1/3)

Oh, I love working with them. ... I'm used to trying to make learning enjoyable, and they came in and they were just fun. (MT1/3)

Like Hodkinson et al. (2005), we found "large amounts of 'underground' working, whereby tutors routinely engaged in working well beyond their job descriptions" (2005:2). A Painting and Decorating tutor who was much appreciated by his apprentices and much in demand during college hours admitted:

I do a lot of work at home and at weekends. I'm contracted to do 24-25 hours direct teaching, and the rest of the time is for preparation work, but it never works out like that. ... I do a lot of material at home, and everyone does. About $25 \%$. It's a bit of a strain, but I have an understanding wife. (A2T1/5) 
Another tutor, working on a course which had had serious staffing problems, was extremely committed to her demanding group of Level 2 students, including some with complex social and ESOL needs, but she admitted that she was regularly working long hours at home, up to 21 hours above her contracted 35 hours, on marking and preparation. Because tutors had complained about the pace of external changes and the constraints on their time and energy resulting from administrative tasks, technological changes, and audit, we specifically asked whether, in their teaching, they felt able to make changes of their own choosing, as opposed to changes required by others. Their replies suggest that most still feel there is space for professional judgement in how they teach, although they have to work within the constraints of the curriculum, the requirements of Awarding Bodies, meeting targets, and passing inspection.

I feel I've a lot of freedom, as long as I get results. (A2T1/4)

If the resources are available, then the changes you choose to make, as long as they're achievable and relevant to what you are doing ... it's pretty much your own management and you're supported within the department. (A1T1/3)

\section{4c Working in teams}

At the level of the teaching team, we found considerable diversity in the degree of contact and co-operation among tutors. Many of our WBL and ACL sites were small, some with only one tutor, which obviously made teamwork difficult, if not impossible. In some college settings too, whose teamwork was much easier to organise, tutors appeared to be working in relative isolation, focusing on their own classes:

I just come in. I've got a job to do and I do it. And there are things on the periphery that I don't get involved with. Simple as that! (C1T1/4)

As long as l've got access to [resources] and my students are not suffering, the policies can stay where they are. (C1T2/1) 
By contrast, in other college settings, managers and tutors stressed the team approach, valuing mutual support and being alert to the possibility that students would exploit any inconsistency in approach by different tutors. Some of the closest teams shared a common professional background, for example, in childcare, where former nursery nurses were confident of their knowledge of the setting that they were preparing learners to work in:

We know what the job entails. We know what employers are looking for. And the current cohort of tutors are all working towards that assumption, that hopefully we are producing nursery nurses that are fulfilling what industry requires. ... It is all about knowing your market. (A1T1/3)

Teamworking is, of course, a standard feature of the working practices within childcare, and the members of this team were also aware they were modelling professional behaviour for their learners. They attached great importance to including their learning support assistants in their team approach, and also involved learners in team-building exercises to foster inclusion and to stifle bullying. In other, less homogeneous teams, such as one teaching Health and Social Care, staff commented on the difficulties caused by the different professional backgrounds of team members. It was possible, however, to develop a culture of strong teamwork even in subject areas which Stanton (2004) describes as 'weakly vocational' ${ }^{4}$, such as Business Studies.

We found two very different approaches in different colleges. In one, a manager was brought in to solve the problem of low retention and achievement rates and created a monitoring system based on the use of a prescribed set of assignments, towards which staff were strongly encouraged to direct all their teaching. Tutors were also told to 'chase the criteria' which students needed to complete assignments and to monitor intensively their attendance and performance. Staff who were not happy to have their roles defined within these parameters were encouraged to leave. In another college, we 
found a Business Studies course team which hit severe staffing problems in 2005-06, to the extent that, on our final visit, we found only two team members out of six still there. The year had put the team under great stress, but their learners were very grateful to them and the staff felt that their difficult year had cemented their teamwork:

We are a strong team, I'd say, probably because of the trials and tribulations we've had. (B2T1/5)

Finally, an important factor which potentially limited teamwork in FE sites was the employment of agency or part-time staff who may not be willing or able to attend team meetings. Some managers stressed that they had negotiated for the funds to enable part-timers to attend meetings.

In the ACL Basic Skills teams, we also found a strong professional identity, fostered by experienced managers who had worked through years of hard times when literacy and numeracy teaching attracted very little political attention or funding. Managers of two large local authority services for basic skills had well-established programmes of inhouse staff development and mentoring. The flurry of activity caused by the introduction of $S f L$, the requirement for staff to take additional, Level 4 qualifications, in Literacy or Numeracy, and a PGCE qualification, and the pressure on experienced staff to take responsibility for mentoring trainees seeking to qualify, had all made it very hard to find times when they could bring the team together.

On WBL sites, the important teamwork was between the tutor who came into the workplace to provide basic skills tuition and the ULRs who were based there, knew the workforce and had the credibility and influence to encourage work colleagues to come forward and become learners. The most successful ULRs in our learning sites were those who saw their role as that of a go-between, as a broker between learners and 
providers: "I haggle with providers ... I play them off against each other" (MU1/2). Such ULRs acted as change agents who made full use of their long and deep knowledge of the learning site and its employees: "I know how to reach them because I am them. I've been there. I've come from there" (MU1/1).

\section{4d Institutional factors}

In the college sites, particular organisational factors influenced learning and inclusion. As Spours et al. (2007) discuss, colleges mediate government policy. This is a complex and cumulative process, comprising not only the acts of translating national policy but also the effects of local and institutional factors. The latter include internal policies, setting their own priorities, making their own decisions about the tightness or looseness of control on departments and staff in areas where targets have to be met, and about whether certain services for students are to be provided at course or department level or centralised and run by college management. Internal decisions are influenced by other cultural and physical factors, including the preferred management style of the principal and senior management team, how they define the community they see themselves serving (are they aiming to attract their traditional clientele, or seeking to attract from wider geographical, social or subject areas?), the quality of communication and the degree of trust between them and their staff, and whether the college is housed on one campus or several.

\section{4e Local and national environmental factors}

Finally, there are wider environmental factors which even college principals cannot control. These include 'local ecologies', a term we use to refer to a wide range of interdependent local relationships and socio-economic factors, including the local labour market, in which FE colleges attempt, alongside many other partners, to provide for the 
learning needs of local people, employers and communities. We certainly found evidence of unhelpful competition between colleges (and between colleges and schools) operating in the same market, and labour markets and local employer attitudes can also have a powerful impact. For instance, a buoyant labour market led to learners being offered full-time jobs before they had completed their apprenticeship framework in one college, which was responding to a shortage of painters and decorators for a local building boom. In the long term this might damage their career opportunities, but in the short term, it damaged the college's completion statistics, and various measures were put in place to encourage the learners to return to take these last few tests. In such circumstances, the efforts that course teams put into developing good working relationships with local employers were almost as important as those expended on the learners.

Other environmental factors are national, rather than local: for example, the buoyancy of the childcare market and the provisions of the Childcare Act 2006 ensure that childcare courses continue to grow. Tutors and course leaders also have to deal with the often taxing requirements of Awarding Bodies, and the Sector Skills Councils were just beginning to make their presence felt as our fieldwork finished.

\section{Discussion}

In this project, we are trying to understand how the LSS functions as a sector, how policy percolates down through the various levels in the system, and how these levels interact, or fail to interact, in the interests of learners. In this paper we have deliberately taken a 'bottom up' approach in order to examine the impact of national policy as it plays out in classrooms, encouraging, for example, some young people to stay on in education by 
means of an EMA. Elsewhere we have taken a more 'top down' view, by reporting the aims, plans and concerns of senior policy-makers, who watch from on high as their measures are either 'misinterpreted' or 'under'- or 'over-interpreted' by institutional leaders and practitioners in the 'front line' (eg Coffield et al., 2005; Spours et al., 2007). We conclude this paper by discussing some of our tentative findings.

First and foremost, we want to argue for a wider recognition of the complexity of the problems being addressed. We have found, for example, little evidence that 'a policy lever pulled' by the LSC in Coventry produces a simple and predictable outcome in the learning sites. Put another way, we have not found evidence of the direct or simple transmission of policy into teaching practices. That is not to say that policy is powerless. Far from it. For example, we have found that policy 'levers' such as targets and funding when they work in combination, powerfully mould the behaviour of institutions and alter professional practices. However, in doing so, they exact high costs (such as intense pressure on staff from constant change and increasing workloads) and produce unintended and perverse consequences (eg the switching of staff time and attention from teaching to coping with bureaucracy). We also found that some senior management teams, faced with the same policy framework felt they could exercise more freedom in translating external policy into internal plans and practices. The broader, more general processes of mediation are affected by different local patterns of provision, the type of institution, management style and professional judgement. This interpretative aspect of our work is far from complete. We are still analysing the data and completing a final round of national interviews to make more sense of recent policy developments and the continually changing face of the LSC. 
The final part of our research envisages potential new relationships between policy and practice through the development of what we have termed 'equitable and effective local learning systems'. More local control, for instance, may bring policy and practice into a closer and more productive relationship, compared with the long and unpredictable journey of national policy 'levers' as they make their way down through the different levels of the LSS.

It is clear that the three areas we studied - FE, ACL and WBL - do not yet see themselves as belonging to a unified sector. And yet they have much in common. For instance, in all three types of learning site, the relationship between tutor and student was seen as paramount; responding to the needs of the students was perceived by tutors as the most important factor of all; and all three were subjected to constant turbulence. Attempts to bring these disparate areas of work closer together could perhaps begin by providing more comparable funding and working conditions for comparable work, which is a genuine bone of contention.

The government is intent on transforming the sector and wishes "to establish a new economic focus for [it], and ensure much greater choice for learning and employers and drive up quality" (Johnson, 2006:2). The scale of the task the government has set itself needs to be appreciated: the LSS covers not only FE Colleges and School Sixth Forms, but also all forms of work based learning for 16-19 year olds and for adults over 19; learning for Personal and Community Development (now known as PCDL); prison education; and support for learners with disabilities and / or difficulties. In total, postcompulsory education and training caters for around 6 million learners; the LSC budget for 2007-08 amounts to $£ 11,390,892,000$ (Johnson, 2006, Annex B); and the workforce in FE alone totals some 600,000 (DfES, 2004:106). One has to admire the attempt to 
change yet again the direction of this many-sided juggernaut: turning round a fleet of oil tankers is simplicity itself in comparison.

Two critical comments, however. First, the budget for PCDL has been falling steadily as a percentage of the LSC's annual funding ie from $2.9 \%$ in $2001-02$ to a projected $1.9 \%$ in 2007-08. Moreover, the phrase "Adult Education" has now disappeared from the vocabulary of the DfES and has been replaced by the term "Adult Skills"; see, for example, its new five year strategy for children and learners, issued in October 2006 (DfES, 2006c). Similarly, the government paper on Reaching Out to the socially excluded (H M Government, 2006) refers neither to education nor to training but to skills.

Second, "greater choice" for adult learners now means being invited to choose any course they like, provided it is an officially approved course which trains them in employability skills. Traditional classes in adult education are closing down throughout the country, despite what we know about the contribution of adult learning to health and social capital (eg, Feinstein et al., 2003).

The Prime Minister's Strategy Unit has also published a new model of public sector reform, which claims to incorporate the "lessons learned over the past nine years" in order to create a "self-improving system" (PMSU, 2006:12). As Figure 4 demonstrates, the model consists of four elements, each of which is intended to exert pressure for change:

- $\quad$ top down performance management, eg targets;

- $\quad$ market incentives, eg competition and contestability;

- $\quad$ users shaping the sector from below, eg so-called 'choice and voice'; 
- $\quad$ increasing the capacity of organisations and the capability of 'the workforce'.

\section{INSERT FIGURE 4 HERE}

This model, which claims to avoid all the limitations (such as perverse incentives) of the 'levers' currently being employed, will bear down hard upon the staff, who will have to contend with pressures coming at them from above, below and from both sides. And yet their experiences, concerns and innovative ideas are conspicuously absent from the model, which contains no systematic feedback loops to enable 'front line' tutors, managers and institutional leaders to report back to policy makers on the strengths and limitations of the new reforms. So those who struggle to make the reforms work and know most about how they impact on practice are excluded from their evaluation and redesign. In other words, the model is a closed system, which claims to have embedded incentives for continuous improvement and innovation, but which instead treats 'the workforce' as another lever to be pulled rather than as creative and socially committed professionals who should be involved in the formation, enactment, evaluation and redesign of policy. In short, professionals in the LSS are neither equal nor full partners in reform, they are the target of reform (see Figure 5).

\section{INSERT FIGURE 5 HERE}

The heart of this paper has been given over to recounting how professionals in FE Colleges, ACL and WBL have struggled to cope with two sets of pressures upon them: those being exerted by government and a broader set of professional, institutional and local factors. In the former category, they have to contend with the combined power of funding, targets and initiatives such as EMA and $S f L$, which have transformed their 
conditions of service, their working practices and the styles of management adopted by institutional leaders. For instance, at the annual conference of the Association of Colleges two leading principals of FE Colleges presented a paper in November 2006 entitled "Only the paranoid survive"

We wish to emphasise, however, that these new "technologies of power", as Janet Newman (2005:6) calls the 'levers', are not all powerful and pervasive, although they set increasingly strict parameters on independent action. The tutors in our sample, for instance, adopted a broad range of responses to policy. We have seen how they use their deep commitment to giving students a second chance by shielding some of their weakest learners from the more perverse effects of funding and targets. They also devise ingenious methods of compliance by, for example, bending (rather than breaking) financial rules to favour their most disadvantaged learners. In short, many still feel they have the space to exercise their most cherished professional values; others who complain of "excessive bureaucracy, ridiculous deadlines and unconvincing consultation process" are taking early retirement (see Arrowsmith, 2006).

The new model of public service reform is, however, likely to diminish the degrees of freedom that professionals currently have. In our judgement, the new battery of key performance indicators is very likely to prove more coercive than enabling, the process of change is likely to become more contested, and the model of reform is unlikely to bring about a speedy transformation of the sector, principally because it treats the workforce' as the main obstacle to progress rather than as indispensable partners. Having explored the complexity of impacts upon practice, we wish to ask: what is the problem in harnessing the knowledge, creativity and energy of staff working in the sector? 
A final story from one of our WBL sites may help to explain the huge cultural changes required to create a learning society in the UK. The senior mangers of a medium sized firm decided to tackle the anti-learning culture which permeated their company by offering, among other incentives, training in leadership to their middle managers. The high profile course lasted a week and even the Managing Director lent his support to the launch. But after a week of training, the Training Manager was shocked to hear one of the participants comment: "What did we do wrong that we need training?"

\section{References}

Arrowsmith. R. (2006) 'Look back in anger', Education Guardian, 8 August.

Bartlett, W., Rees, T. and Watts, AG (2000) Adult guidance services and the learning society, (Bristol, The Policy Press).

Coffield, F., Steer, R., Hodgson, A., Spours, K., Edward, S. and Finlay, I. (2005) A new learning and skills landscape? The central role of the Learning and Skills Council, Journal of Education Policy, 20 (5) 631-656.

Coffield, F. and Edward, S. (forthcoming) Rolling out 'good', 'best' and 'excellent' practice. What next? Perfect practice? British Educational Research Journal.

DFEE (2001) Skills for Life: the national strategy for improving adult literacy and numeracy skills (London, DfEE).

DfES (2003) Skills for Life: The national strategy for improving adult literacy and numeracy skills. Focus on delivery to 2007 (London, DfES).

DfES (2004) Five year strategy for children and learners, Cm6272. (London, The Stationery Office).

DfES (2006a) Further Education: raising skills, improving life chances (London, DfES).

DfES (2006b) Delivering the Further Education (FE) book of facts (London, DfES). 
DfES (2006c) The five year strategy for children and learners: maintaining the excellent progress (Sherwood Park, DfES).

Edward, S., Coffield, F., Steer, R. and Gregson, M. (2007) Endless change in the learning and skills sector: the impact on teaching staff, Journal of Vocational Education and Training, 59 (2), in press.

Feinstein, L., Hammond, C., Woods, L., Preston, J and Bynner, J (2003) The contribution of adult learning to health and social capital (London, Institute of Education, Centre for Research on the Wider Benefits of Learning).

Finlay, I., Hodgson, A. and Steer, R. (2007) Flowers in the desert: the impact of policy on basic skills provision in the workplace, Journal of Vocational Education and Training, 59 (2), in press.

Finlay, I., Spours, K., Steer, R., Coffield, F., Gregson, M., and Hodgson, A. (2007) "The heart of what we do": policies on teaching, learning and assessment in the learning and skills sector, Journal of Vocational Education and Training, 59 (2), in press.

HM Government (2006) Childcare Act 2006. (London, HMSO)

H M Government (2006) Reaching out: an action plan on social exclusion, (London, Cabinet Office).

Hodgson, A., Edward, S. and Gregson, M. (2007) Riding the waves of policy? The case of basic skills in adult and community learning in England, Journal of Vocational Education and Training, 59 (2), in press.

Hodgson, A., Spours, K., Coffield, F., Steer, R., Finlay, I., Edward, S. and Gregson, M. (2005) A new learning and skills landscape? The LSC within the learning and skills sector. ESRC TLRP Project research report 1 (London, Institute of Education, University of London).

Hodgson, A., Steer, R., Spours, K., Edward, S., Coffield, F., Finlay, I. and Gregson, M. (2007) Learners in the learning and skills sector: the implications of 'half-right' policy assumptions, Oxford Review of Education, 33 (3), in press.

Hodkinson, P., Biesta, G., James, D., Gleeson, D. and Postlethwaite, K. (2005) Improving learning in further education: a new cultural approach. TLRP research briefing 12 (London, TLRP). 
House of Commons, Committee of Public Accounts (2006) Skills for Life: improving adult literacy and numeracy. Twenty-first report of Session 2005-06. HC 792 (London, The Stationery Office). Johnson, A. (2006) LSC Grant Letter: 2007-08 (London, DfES).

LSC (2005) Learning and skills - the agenda for change: the prospectus (Coventry, LSC).

LSC (2006a) Learning for living and work: improving education and training opportunities for people with learning difficulties and / or disabilities (Coventry, LSC).

LSC (2006b) Framework for excellence: a comprehensive performance assessment framework for the Further Education system (Coventry, LSC).

Leitch, S. (2006) Prosperity for all in the global economy - world class skills. Final report (London, HMT).

Newman, J. (2001) Modernising governance: New Labour, policy and society (London, Sage).

Newman, J. (2005) Beyond the New Public Management? Modernizing Public Services in Clarke, J., Gewirtz, S. and McLaughlin, E. (Eds) New Managerialism, New Welfare? (London, Sage, pp.45-61).

Nias, J. (1989) Primary teachers talking (London, Routledge \& Kegan Paul).

OECD (2006) Education at a glance (Paris, OECD).

Prime Minister's Strategy Unit (2006) The UK Government's approach to public service reform a discussion paper (London, Cabinet Office).

Quality Improvement Agency for Lifelong Learning (2007) Pursuing excellence: the national improvement strategy for the further education system. (Coventry, QIA).

Spours, K., Coffield, F. and Gregson, M. (2007) Mediation, translation and local ecologies: understanding the impact of policy levers on FE colleges, Journal of Vocational Education and Training, 59 (2), in press.

Stanton, G. (2004) The organisation of full-time 14-19 provision in the state sector. Nuffield 14-19 Review working paper 13. www.nuffield14-19review.org.uk/documents.html accessed September 2006. 
Steer R., Spours, K., Hodgson, A., Finlay, I., Coffield, F., Edward, S. and Gregson, M. (2007) 'Modernisation', learning and skills: policy drivers and policy levers in the English learning and skills sector'. Journal of Vocational Education and Training, 59 (2), in press.

Stronach, I., Corbin, B., McNamara, O., Stark, S., and Warne, T (2002) Towards an uncertain politics of professionalism: teacher and nurse identities in flux, Journal of Education Policy, 17, 1, 103-138. 
1 The researchers wish to acknowledge the funding of this project by the ESRC - reference number RES139-25-0105.

${ }^{2}$ Coffield et al. (2005) and Hodgson et al. (2005) discuss the structure of the sector as revealed by the early policy interviews; Hodgson et al. (2007) review the learning site data collected by summer 2005 from learners. A special issue of Journal of Vocational Education and Training is in press, including further papers on policies on teaching, learning and assessment (Finlay et al.); the impact of endless change on teaching staff (Edward et al.); the use of policy steering mechanisms (Steer et al.) and on each of the three types of learning site: FE colleges (Spours et al.), Adult and Community Learning (ACL) (Hodgson et al.) and Work Based Learning (WBL) (Finlay et al.).

${ }^{3}$ See Coffield and Edward, forthcoming, for a critique of the notion of 'good practice.'

${ }^{4}$ The term 'weakly vocational' does not refer to the quality of the pedagogy, but to a course where staff are unlikely to share similar backgrounds, and where learners are often uncertain about their future career intentions, rather than preparing to follow a clear vocational path.

${ }^{5}$ The presenters were Jackie Fisher, Principal, Newcastle College and Willie Mills, Principal, City College Manchester. 